\title{
Alu Elements Support Independent Origin of Prosimian, Platyrrhine, and Catarrhine Mhc-DRB Genes
}

\author{
Karin Kriener, Colm O'hUigin, and Jan Klein ${ }^{1}$ \\ Max-Planck-Institut für Biologie, Abteilung Immungenetik, D-72076 Tübingen, Germany
}

\begin{abstract}
The primate major histocompatibility complex (Mhc) genes fall into two classes and each of the classes into several families. Of the class II families, the DRB family has a long and complex evolutionary history marked by gene turnover, rearrangement, and molecular convergence. Because the history is not easily decipherable from sequences alone, Alu element insertions were used as cladistic markers to support the surmised phylogenetic relationships among the DRB genes. Intron 1 segments of $24 D R B$ genes from five platyrrhine species and five DRB genes from three prosimian species were amplified by PCR and cloned, and the amplification products were sequenced or PCR-typed for Alu repeats. Three Alu elements were identified in the platyrrhine and four in the prosimian DRB genes. One of the platyrrhine elements (Alu50) is also found in the Catarrhini, whereas the other two (Alu62SC, Alu63SC) are restricted to the New World monkeys. Similarly, the four prosimian elements are found only in this taxon. This distribution of Alu elements is consistent with the phylogeny of the DRB genes as determined from their intron 1 sequences in an earlier and the present study. It contradicts the exon 2-based phylogeny and thus corroborates the conclusion that the evolution of DRB exon 2 sequences is, to some extent, shaped by molecular convergence. Taken together, the data indicate that each of the assemblages of DRB genes in prosimians, platyrrhines, and catarrhines is derived from a separate ancestral gene.
\end{abstract}

[The sequence data described in this paper have been submitted to the GenBank data library under accession nos. AF197226-AF197240.]

The major histocompatibility complex $(M h c)$ is a multicomponent assemblage comprised of genes of different age (Parham 1999). All jawed vertebrates possess two classes of $M h c$ loci and in each class there are several families of genes whose divergence times differ depending on the taxonomical position of the animal (Klein 1986; Klein and Figueroa 1986; Kasahara et al. 1995). In primates, a few of the class I loci diverged prior to the emergence of this order, but most are of much more recent origin (Hughes and Nei 1989a). The primate class II gene families $D O, D P, D Q$, and $D R$, on the other hand, diverged before the radiation of the eutherian mammals (Carson and Trowsdale 1986). Within the families, the loci can vary considerably in their ages (Satta et al. 1996a,b). Loci of the DRB subfamily in particular appear to have undergone frequent expansions and contractions (Klein et al. 1993) that considerably obscured their evolutionary history. The deciphering of their history is further complicated by the fact that parts of the genes are subject to convergent evolution (Andersson et al. 1991; Kriener et al. $2000 a, b)$. Interpreting the evolution of these genes is therefore a daunting task, which can succeed only if based on a combination of different approaches and utilization of a variety of marker systems.

'Corresponding author.

E-MAIL jan.klein@tuebingen.mpg.de; FAX 49 7071/600437.
In earlier publications (Kriener et al. 2000a,b), we provided evidence that exon 2 sequences, on which previous phylogenies of primate $D R B$ genes were based (Trtková et al. 1993; Figueroa et al. 1994; Gyllensten et al. 1994), are providing misleading phylogenetic signals. The evolution of the exon is strongly affected by positive selection (Hughes and Nei 1989b), which creates repeatedly and independently similar sequence motifs (O'hUigin 1995; Kriener et al. 2000a,b). These motifs make genes appear more closely related than they are in reality. This, at least, is the message extracted from comparisons of the $D R B$ intron with the $D R B$ exon 2 sequences. Specifically, whereas the exon 2 sequences suggest that most primate $D R B$ genes derive from a common ancestor that existed prior to the divergence of prosimians, Platyrrhini, and Catarrhini, intron sequences support the origin of $D R B$ genes in each of the three taxa from a distinct ancestor (Kupfermann et al. 1999; Kriener et al. 2000a,b). Analysis of the exon 2 similarities implies molecular convergence as an explanation and thus indicates that the introns and not exon 2 are reflecting the true $D R B$ gene phylogeny. However, as both the exon 2 and intron data are sequence-based, an independent source of information corroborating these conclusions was needed. We sought this source in the Alu elements inserted into the $D R B$ genes. 
The use of short interspersed repetitive elements (SINEs) in phylogenetic analysis is widespread. They have been used successfully to resolve phylogenies of a variety of mammals and other vertebrates (Batzer et al. 1994; Shimamura et al. 1997; Stoneking et al. 1997; Hamdi et al. 1999; Nikaido et al. 1999). They offer the advantages of ubiquity, uniqueness, and stability. Insertion occurs often enough to provide an array of useful cladistic markers. The chance of independent insertions at identical positions is small. Finally, SINEs are rarely removed without leaving evidence of their previous presence.

Alu repeats constitute one of several families of SINEs found in the mammalian genome (Deininger and Batzer 1993; Jurka 1995). They are believed to be derived from the 7SL RNA, which is a part of an $11 \mathrm{~S}$ cytoplasmic ribonucleoprotein involved in targeting secretory proteins across the membranes of the endoplasmic reticulum (Ullu and Tschudi 1984). The derivation occurred in multiple steps in which two variants were first produced by deletions in different parts of the 7SL RNA gene - the free left Alu monomer or FLAM and the free right Alu monomer or FRAM - and these monomers then fused to form the dimeric Alu elements (Quentin 1992a,b). All three forms are still found in the primate genome. The dimeric family of Alu elements is divided into three major subfamilies that are of different age, and which, in the standardized nomenclature of Batzer et al. (1996), are designated J ( 80-million-years [my] old), S ( 35-44-my old), and Y ( $<5$-my old). Each subfamily is further divided into sub-subfamilies (e.g., the S subfamily is differentiated into $\mathrm{Sx}, \mathrm{Sy}, \mathrm{Sp}$, and Sc branches). The subfamilies and the sub-subfamilies are distinguished by diagnostic substitutions shared by all members of a given group. The Alu elements are retroposons owing their mobility to the possession of sequences enabling their transcription by RNA polymerase III.

As Alu elements are ubiquitous in the primate genome, they can be identified relatively easily in any genomic region of interest. In earlier studies, we identified a series of $>60$ Alu elements in the catarrhine Mhc-DRB genes (Schönbach and Klein 1991; Mňuková et al. 1994; Satta et al. 1996a) and designated them Alu1-Alu61. The aim of the present study was to identify platyrrhine and prosimian DRB gene-associated Alu elements and use them to resolve the incongruences between the exon 2- and intron-based phylogenies.

\section{RESULTS}

In our search for Alu markers suited to the stated purpose, we focused on intron 1 because of its proximity to exon 2, which is the most variable of all the $D R B$ exons, because of its length of several kilobase pairs (kb), which increases the likelihood of repeats' pres- ence, and because several Alu elements were identified in it in catarrhine $D R B$ genes (Andersson et al. 1987; Mňuková et al. 1994; Satta et al. 1996a), including one old element (Alu50J). To identify Alu elements in platyrrhine $D R B$ genes, we selected seven genomic New World Monkeys (NWM) DNA samples bearing previously identified $D R B$ exon 2 sequences (Trtková et al. 1993). Using exon 1- and exon 2-based primers, we then attempted to amplify the entire intron 1 and most of exon 2 of the different $D R B$ genes by PCR. We succeeded in amplifying segments from 24 different $D R B$ genes and failed with 5 , perhaps because of a too large intron length. We confirmed the identity of the 24 amplification products by cloning them and sequencing their ends, including exon 2. For 23 of the 24 clones, the exon 2 sequences have already been described (Trtková et al. 1993; Gyllensten et al. 1994; Antunes et al. 1998; Kriener et al. 2000a, b), whereas one sequence identified a new exon 2 , which we designate $S a s c-D R B^{\star} W 3401$. Ten of the 24 amplification products were chosen for restriction digest and hybridization analysis.

Samples of each of the 10 clones were divided into three parts and each part was digested with a different pair of restriction enzymes (BamHI-HindIII, HindIIIHincII, and BamHI-EcoRI). The digests were separated by gel electrophoresis, blotted, and the blots were hybridized with an Alu-specific probe (Fig. 1). The probe was obtained by PCR amplification of human genomic DNA using primers Alu1 and Alu2 (Table 1). It was 250-bp long and was shown in control experiments to hybridize with members of the $\mathrm{J}, \mathrm{Sb}, \mathrm{Sc}$, and Sq subfamilies of Alu elements. By use of this probe, one or two hybridizing fragments could be identified on the blots of the digested NWM clones. The positive fragments were then subcloned and sequenced. The sequences were aligned and the Alu elements in them identified (Fig. 2).

This approach revealed the presence of three distinct $A l u$ elements in platyrrhine $D R B$ intron 1 sequences. One of these three elements, Alu50, was identified previously in catarrhine $D R B$ genes (Mňuková et al. 1994), the other two are new and so we designated them Alu62 and Alu63. The identification of the first element as Alu50 is based on sequence similarity and sharing of flanking direct repeats, as well as its position and orientation in intron 1 (Figs. 2 and 3). By some of the same criteria, Alu62 and Alu63 are distinct from all other Alu elements identified thus far, which means that they are absent in all of the analyzed catarrhine $D R B$ genes. The Alu50 element was found to be present in all 10 clones; Alu62 and Alu63 were present in some of them and absent in others (Fig. 2).

The presence or absence of the three Alu elements among the remaining 14 of the 24 clones (i.e., those not subjected to restriction enzyme analysis) was es- 


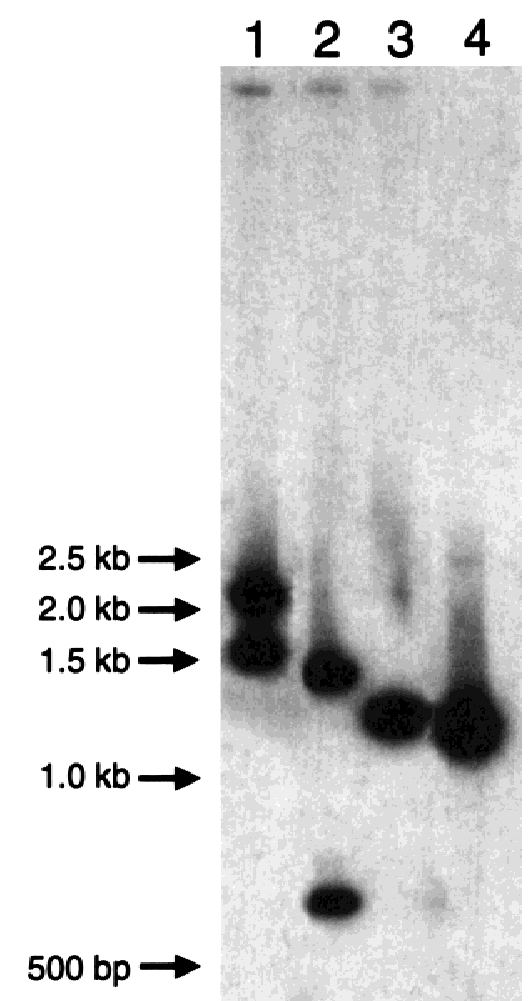

Figure 1 Southern blot analysis of a Saoe-DRB 11*0102 intron 1 clone. The clone was digested with different pairs of restriction enzymes. The digests were separated by gel electrophoresis, blotted, and the blot hybridized with an Alu-specific probe. (Lanes 1-3) Digests obtained after treatment with the BamHI/HindIII, HindIII/Hincll, and BamHI/EcoRI enzymes, respectively.(Lane 4) Positive control. A 1.2-kb fragment containing Alu50/ was amplified from human genomic DNA and blotted.

tablished by PCR typing. To this end, the DNA isolated from the individual clones was PCR amplified by using different combinations of primers specific for each of the three Alu elements (Table 1; Fig. 4). The specificity of the primers was based on the uniqueness of the sequences flanking the individual Alu elements. The typing identified Alu50 in all 14 clones; Alu62 in SaoeDRB11*0105, Caja-DRB1*0307, Caja-DRB*W1602, Caja-DRB*W1603, Caja-DRB*W1605, Caja$D R B^{*} W 1612$, Sasc-DRB*W1401, Sasc-DRB*W1901, Sasc-DRB*W3401, Ceap-DRB*W1301, and Ceap$D R B^{*} W 1502$; and Alu63 in Saoe-DRB11*0105, Caja$D R B 1^{*} 0307$, Caja-DRB*W1602, Caja-DRB*W1603, Caja-DRB*W1605, Caja-DRB*W1612, Sasc$D R B^{*} W 1901$, and Ceap-DRB*W3201. [The Alu50 element is present in all catarrhine $D R B$ genes tested except Maar-DRB1*0301, in which the Alu50 region of intron 1 has been deleted (K. Kriener unpubl.). The Alu62 and Alu63 elements, as already mentioned, are absent in all identified catarrhine $D R B$ genes.]

The Alu50, Alu62, and Alu63 elements are located in the same region of intron 1, arranged in this order in the $5^{\prime}$ to $3^{\prime}$ direction, $\sim 1.2 \mathrm{~kb}$ downstream from the $5^{\prime}$ end of intron 1 (Fig. 3). Where all three elements are present on the same clone, Alu62 is immediately adjacent to Alu50 in a head-to-head orientation and Alu63 is $\sim 270$ bp downstream of Alu62 in the same orientation as Alu62. In the same region, different Alu elements are found in both catarrhini (Alu29; Satta et al. 1996a) and prosimians (see below). The region therefore appears to be highly prone to Alu insertions. Sequence comparisons (Fig. 2) and analysis of diagnostic sites (Jurka and Milosavljevic 1991), as well as phylogenetic analysis of the sequences (Fig. 5), assign both Alu62 and Alu63 to the Sc subfamily.

To investigate Alu elements of prosimian $D R B$ genes, we used the exon 1- and exon 2-based primers on genomic DNA isolated from three prosimian species to amplify intron 1 of these genes by PCR. The amplification products, which ranged in length from 3.5 to $10 \mathrm{~kb}$, depending on the species and the gene, were cloned, the clones digested with restriction enzymes, the fragments separated by electrophoresis and blotted, and the blots hybridized with an Alu-specific probe. The enzymes and the probe used were the same as those used in the study of the platyrrhine $D R B$ genes. The weakly hybridizing fragments of five clones (three from Galago moholi and one each from Tarsius syrichta and $T$. bancanus) were subcloned and sequenced. The sequences revealed the presence of four different Alu elements. Three of them, found in the Galago, could be identified by sequence comparisons as dimeric type II repeats characteristic for galago genomes (Daniels and Deininger 1985, 1991). Because the three elements are distinct from each other and from all previously identified, DRB-associated Alu repeats, we designate them Alu64, Alu65, and Alu66. Alu64 is located in a region corresponding to that occupied in the platyrrhini by Alu50, Alu62, and Alu63; Alu65 is found $700 \mathrm{bp}$ downstream of Alu64; Alu66 is located at the 3 ' end of intron 1. The Alu64 and Alu65 elements are present in the Gamo-DRB*W301 gene; the Alu66 element in the Gamo-DRB*W401 and *W501 genes. The fourth element, designated Alu67, was found in the two tarsier species; it resembled the recently described tarsier-specific type of elements (Zietkiewicz et al. 1999). It occurred at the $3^{\prime}$ end of intron 1 in the Tasy-DRB*W101 and Taba-DRB*W201 genes. Neither Alu50, which is present in virtually all platyrrhine and catarrhine $D R B$ genes, nor any of the other $A l u$ elements identified previously in $D R B$ genes could be found in any of the prosimian genes. The presence in the prosimian genes of a single copy of the sequence that flanks both ends of the Alu50 element (data not shown) indicates that Alu50 was apparently never present in these genes. The prosimian genes possess an entirely different set of Alu elements than the $D R B$ genes in Platyrrhini and Catarrhini.

To determine the relationship of the Alu-element 
Table 1. Oligonucleotide Primers Used for PCR Amplification

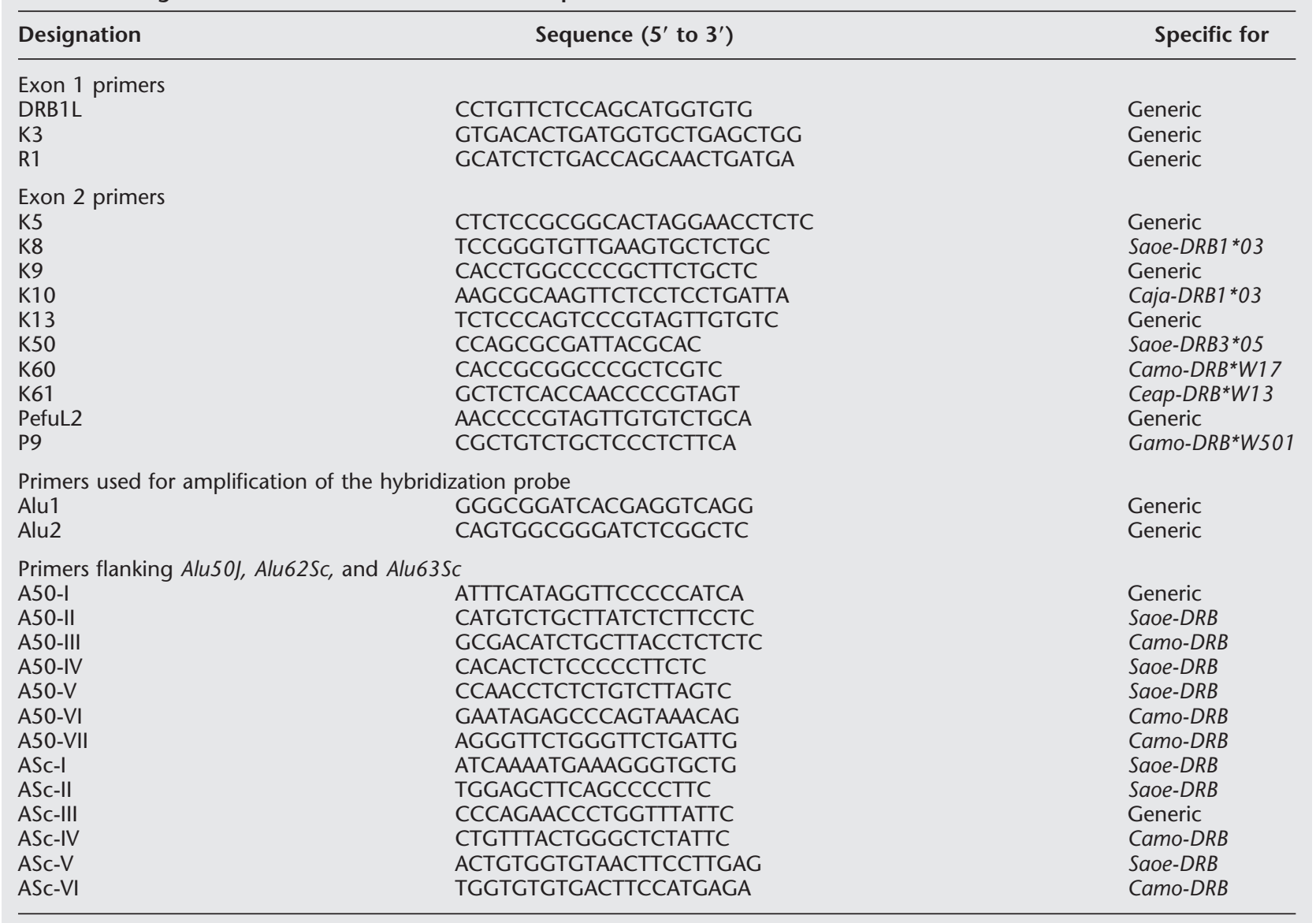

distribution to the phylogeny of the $D R B$ genes, we superimposed the former on the latter in Figure 6 . The tree in Figure 6 is based on $\sim 600$ bp of sequence at the 5' end of intron 1 (Kriener et al. 2000a; Fig. 3), in addition to $\sim 500$ bp of sequence flanking the Alu elements. The sequences of the Alu region were submitted to GenBank (accession nos. AF197226-AF197240). The presence or absence of the Alu elements shows no correlation with either the species of origin of the DNA or the exon 2-based DRB gene classification as reflected in the gene designations. In contrast, the Alu element distribution correlates with the intron 1 phylogeny, which also correlates with the presence or absence of a previously described 870-bp deletion at the 3' end of the platyrrhine intron 1 (Kriener et al. 2000a,b; Fig. 3). Because the deletion is absent in all tested catarrhini $D R B$ genes, it apparently arose in an ancestral gene within the platyrrhine clade.

\section{DISCUSSION}

In the preceding text, we regarded the primate order as consisting of three monophyletic groups, the prosimians, the platyrrhines, and the catarrhines. Although the monophyly of the last two groups has never been seriously contested, that of the prosimians is contentious (Martin 1990), and we used the traditional designation merely as a convenient way of referring to non-anthropoid primates. Recent molecular evidence, in fact, strongly bolsters the splitting of prosimians into Strepsirrhini and Haplorrhini, the latter being a sister group of Anthropoidea (Goodman et al. 1998). The Strepsirrhini include lemurs and galagos, the Haplorrhini the tarsiers. The existence of separate sets of Alu elements in galagos and tarsiers (Daniels and Deininger 1985, 1991; Zietkiewicz et al. 1999; the present report) provides additional evidence for this split. The apparent polyphyly of the prosimians must be taken into account when interpreting the results of the present study.

Considered in the context of previous work on primate DRB genes in our laboratory (Trtková et al. 1993, 1995; Figueroa et al. 1994; Kriener et al. 2000a,b; Kupfermann et al. 1999) and in other laboratories (Slierendregt et al. 1992; Gyllensten et al. 1994; Knapp et al 1997; Antunes et al. 1998), the results described here lead us to two conclusions. The first conclusion is that in each of the four main primate groups (Strepsirrhini, 


\section{Platyrrhini}

Alu50J

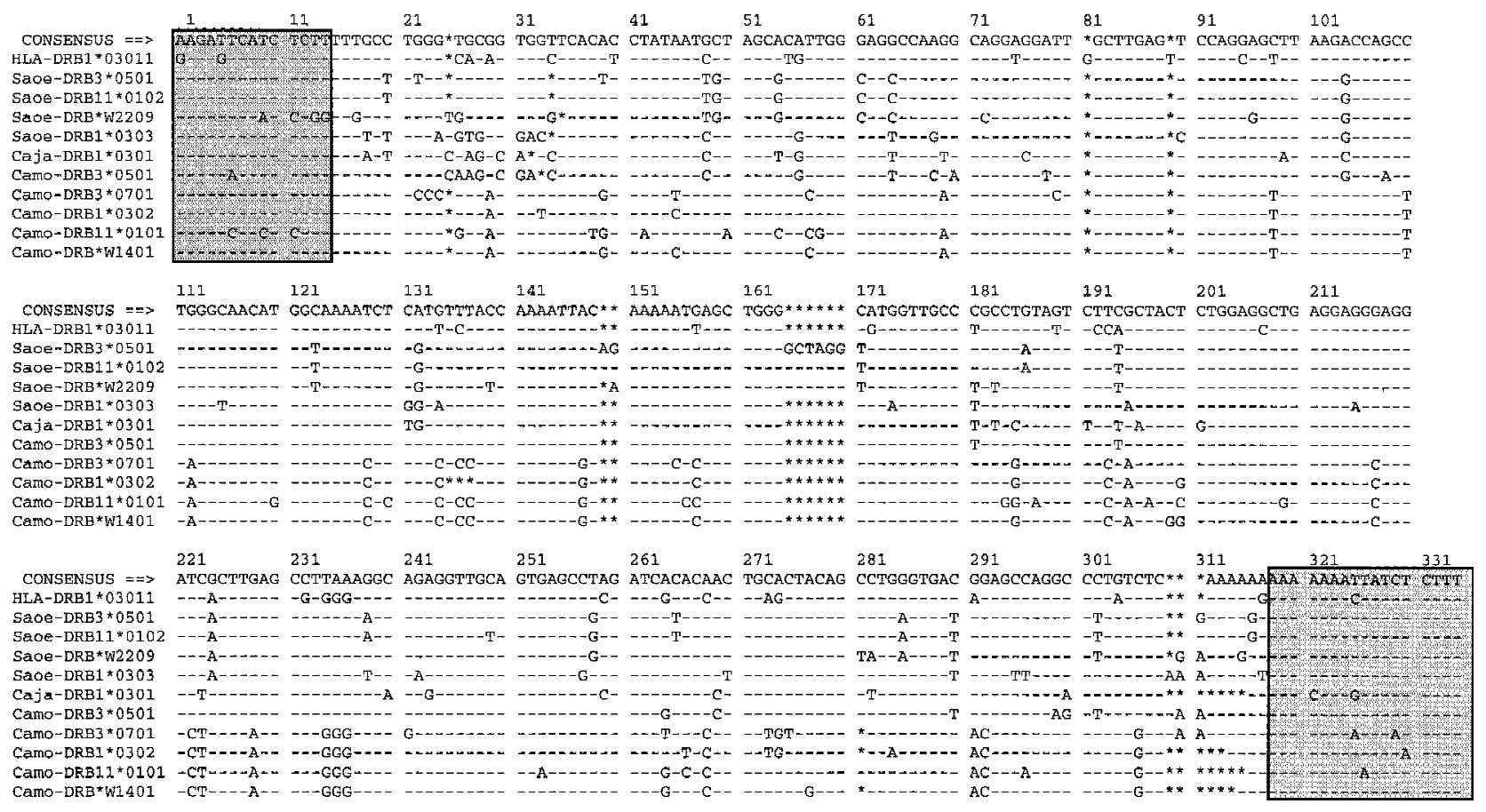

\section{$\operatorname{Alu} 62 \mathrm{Sc}$}

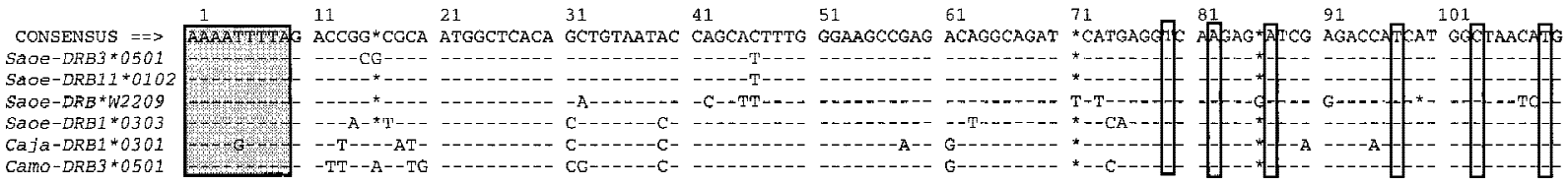

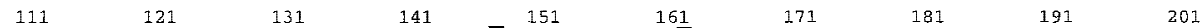

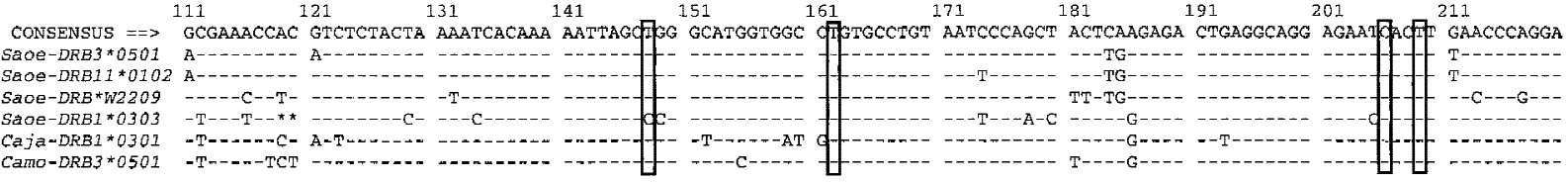

Caja-DRBI 0301 -T

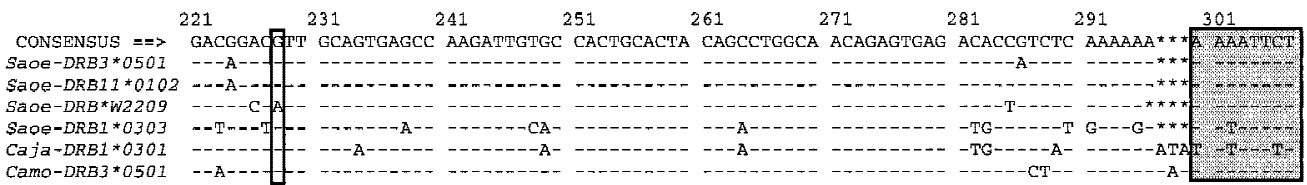

\section{Alu63Sc}

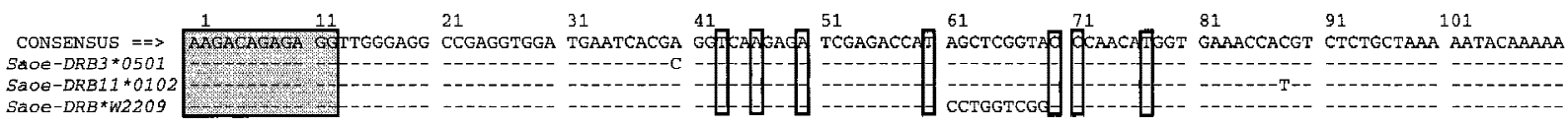

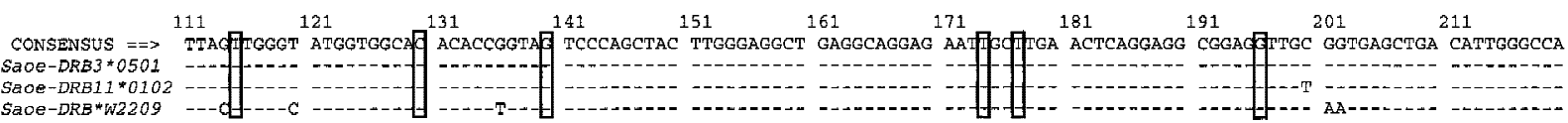

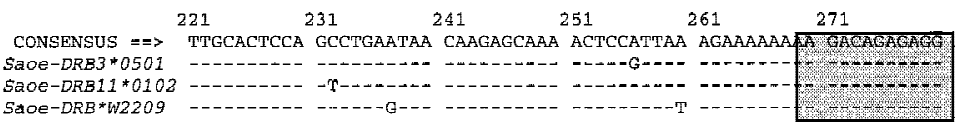

Figure 2 (See facing page for legend.)

\section{Genome Research}




\section{Strepsirrhini}

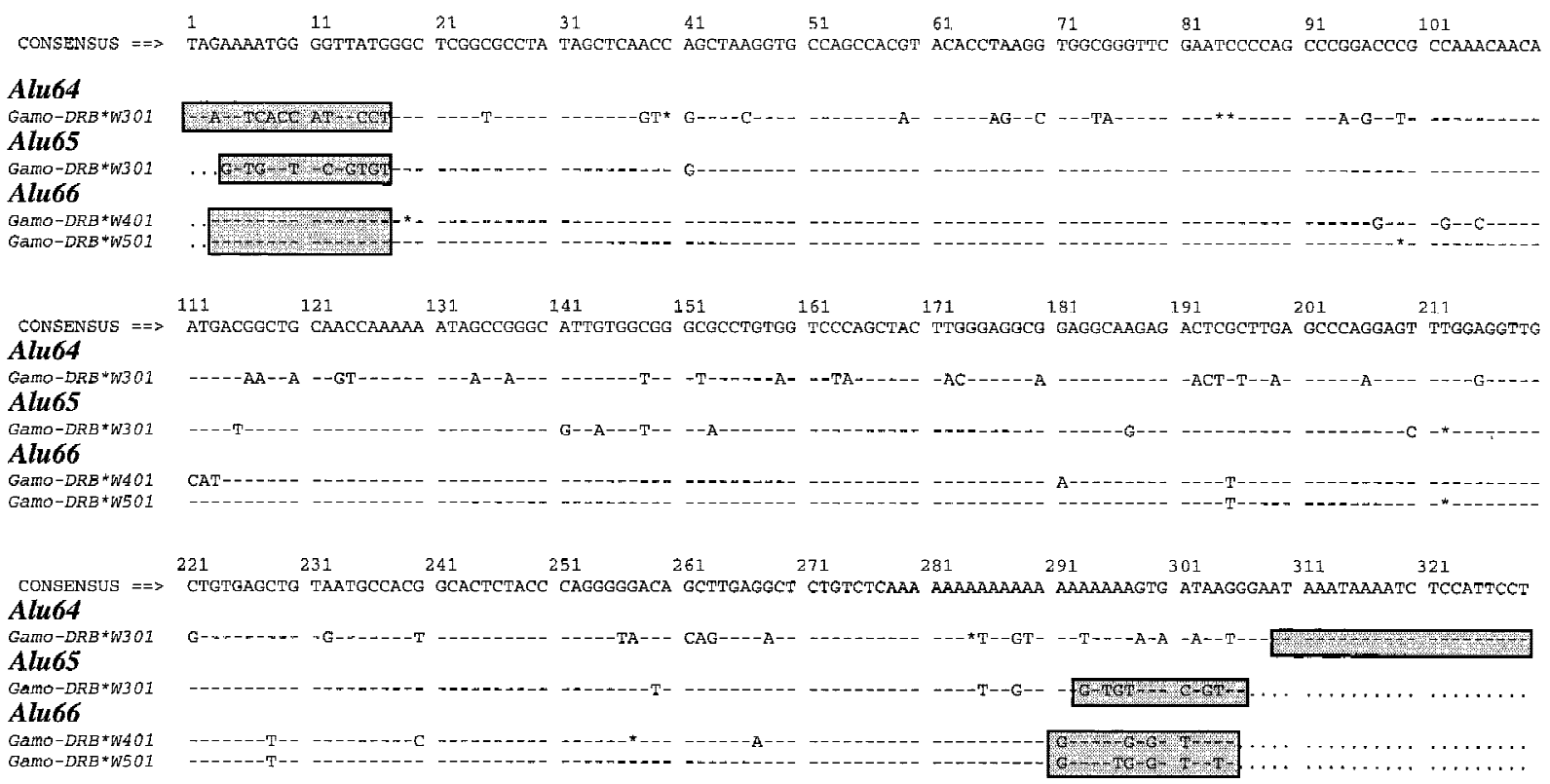

\section{Haplorrhini}

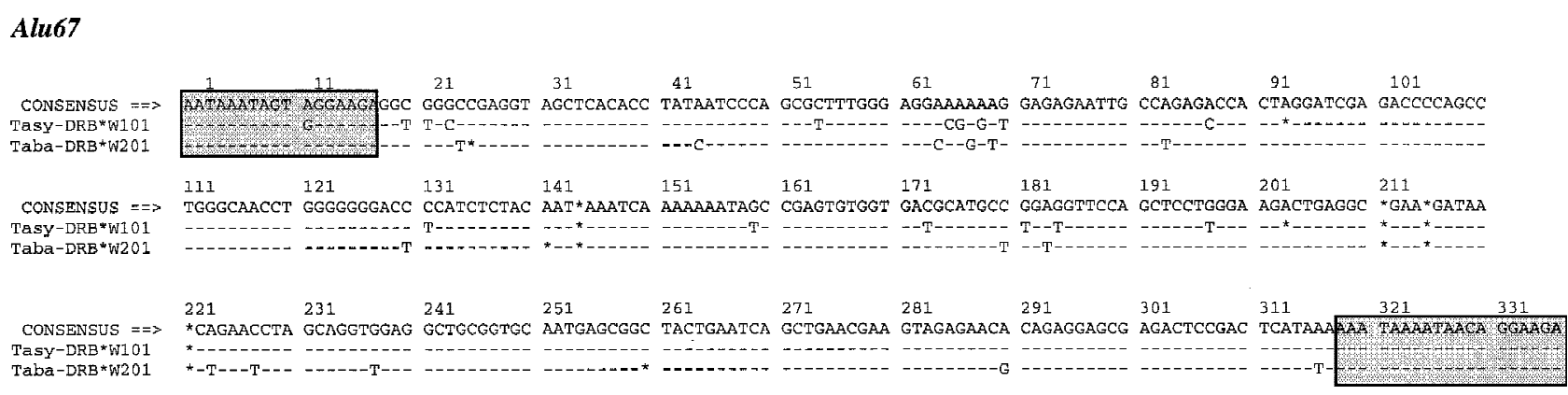

Figure 2 Nucleotide sequence alignments of the Alu elements identified in the DRB genes of platyrrhini, strepsirrhini, and haplorrhini. The shaded boxes represent the flanking direct repeats that are created during the insertion of the Alu element. In Alu62 and Alu63, the diagnostic positions used for the subfamily classification are highlighted. A simple majority consensus sequence is given at the top. A dash (-) indicates identity with the consensus, an asterisk $\left(^{*}\right)$ an indel, and a dot (.) unavailability of sequence information. Numbering above the sequences starts with the first nucleotide of the alignment.

Haplorrhini, Platyrrhini, and Catarrhini), there are multiple $D R B$ loci present. This claim is best supported by data available for the Catarrhini, in which multiple loci have actually been assigned to their respective positions on genetic maps (Klein et al. 1991). In humans, for example, nine $D R B$ loci are known to exist, although they never occur all together on one chromosome (Klein et al. 1991). For the Platyrrhini, Haplorrhini, and Strepsirrhini the claim is largely based on the detection of more than two $D R B$ sequences per individual (Trtková et al. 1993; Figueroa et al. 1994; Gyllensten et al. 1994; Antunes et al. 1998; the present study). The organization of the loci is not known in any of these groups. The observation that different numbers of sequences are amplified from various indi- viduals can, however, be taken as a hint that the number of loci per haplotype varies in the same manner as it does in human $D R B$ haplotypes.

The second conclusion is that in each of the four primate groups, the $D R B$ genes derive from a separate ancestral gene. The four ancestors all in turn derive from a single gene that was the last common ancestor of all primate $D R B$ genes. The existence of an ancestral primate gene separate from the ancestral genes of $D R B$ loci in other orders of eutherian mammals is suggested first, by intron sequence-based phylogenies (Kriener et al. 2000a,b; Kupfermann et al. 1999; Fig. 6), and second, by the types and distribution of the DRBassociated Alu elements (Schönbach and Klein 1991; Mňuková et al. 1994; Satta et al. 1996a; the present 


\section{Catarrhini}

HLA-DRB2

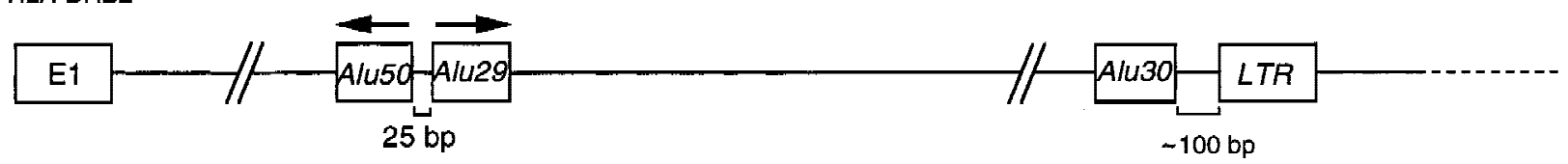

\section{Platyrrhini}

Saoe-DRB3*0501

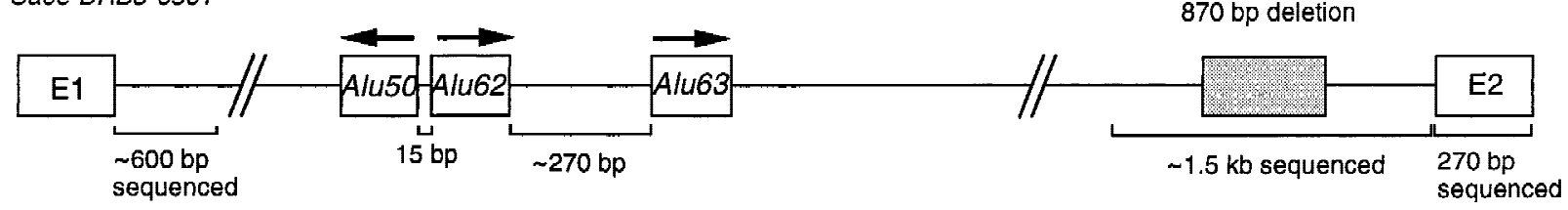

\section{Strepsirrhini}

Gamo-DRB*W301

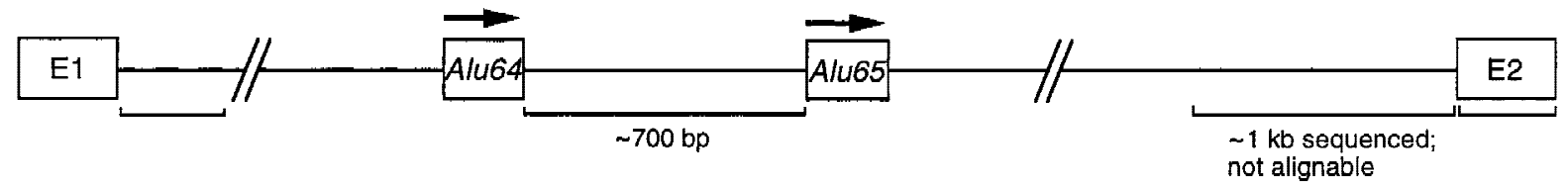

\section{Haplorrhini}

Tasy-DRB*W101

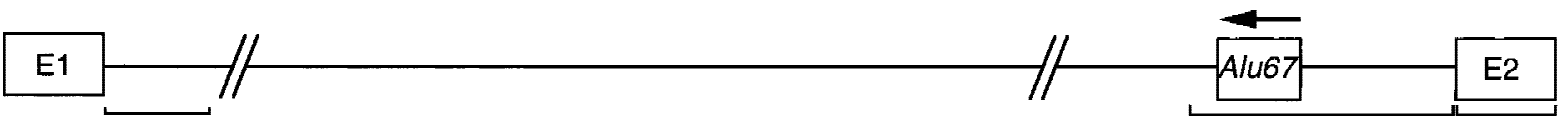

Figure 3 Diagram of intron 1 of selected catarrhine, platyrrhine, and prosimian DRB genes. The Alu elements identified in the intron are shown and their orientation is indicated by arrows. The distances between the Alu elements and the length of sequenced fragments in the $5^{\prime}$ and the $3^{\prime}$ ends of intron 1 are indicated by brackets. The shaded box represents a 870-bp deletion in the $3^{\prime}$ end of intron 1 . The drawing is not to scale.

study). The intron sequence data are fully congruent with the Alu distribution results. Each of the four primate groups has a monophyletic set of $D R B$ intron sequences and each has a distinct set of $A l u$ elements. The only shared element is Alu50 (a member of the oldest subfamily of elements), which is found in both the Platyrrhini and Catarrhini; all of the others are restricted in their distribution to only one of the four groups. The sharing of Alu50 supports the grouping of Platyrrhini and Catarrhini into Anthropoidea. The group restriction of the other Alu elements supports the monophyly of each of these groups and of the $D R B$ genes in the Strepsirrhini, Haplorrhini, Platyrrhini, and Catarrhini. The group restriction is also found in the shorter downstream introns surveyed by Kupfermann et al. (1999). This distribution pattern is consistent with the assumption that new elements became inserted into the $D R B$ genes in each of the four primate groups as they diverged from each of their common ancestors.

The above interpretation is seemingly contradicted by the exon 2-based phylogenies of the $D R B$ genes (Trtková et al. 1993; Gyllensten et al. 1994; Figueroa et al. 1994). These phylogenies lead to the conclusion that separate allelic lineages at $D R B$ loci diverged before the divergence of primates into the four

\section{Intron 1}

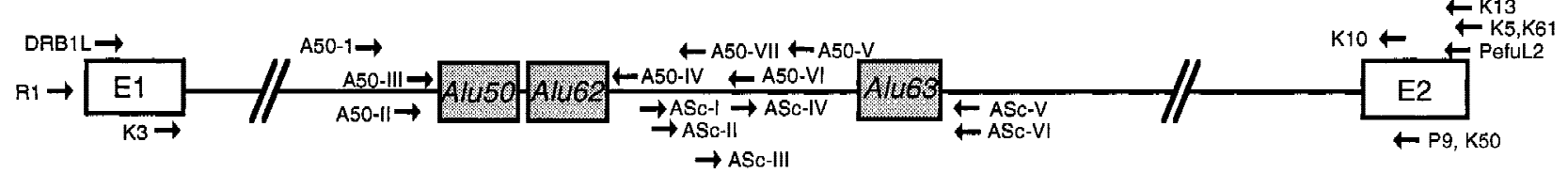

Figure 4 Location of the primers used for PCR amplifications. Primers (arrows) located in exon 1 and exon 2 were used to amplify the entire intron 1 of DRB genes. The cloned products were typed for the presence of Alu50, Alu62, and Alu63 with combinations of the primers Alu50-I-Alu50-VII and AluSc-I-AluSc-VI. The sequences of the primers are given in Table 1. (E) Exon, the shaded boxes represent Alu elements. 


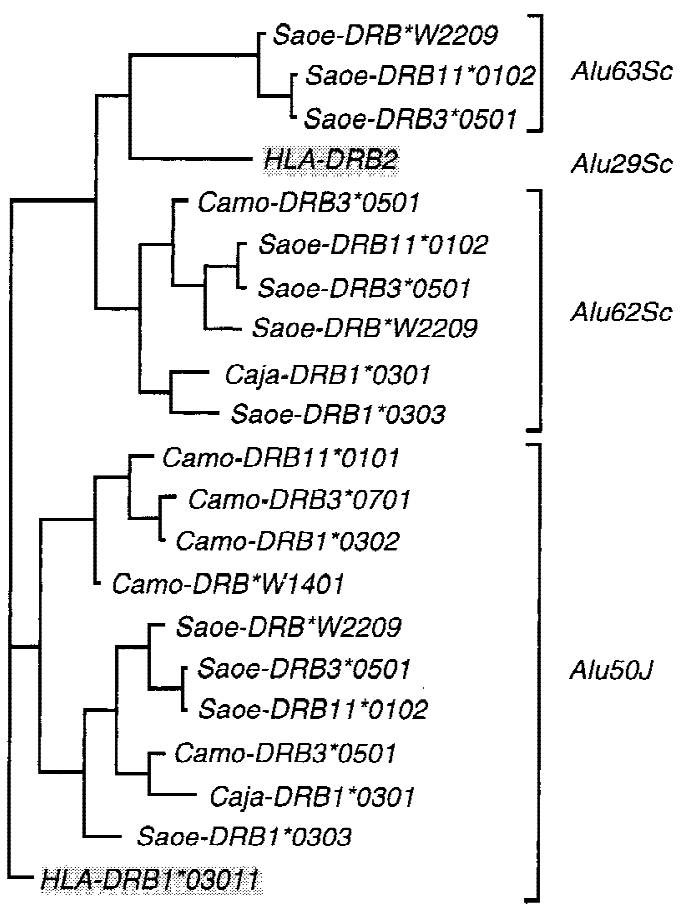

Figure 5 Maximum likelihood tree based on the sequences of human and NWM Alu elements (Fig. 2). The classification of Alu62 and Alu63 in the Sc subfamily is supported by their grouping with Alu29 of the HLA-DRB2 gene. Sequences of Alu50 from the $H L A-D R B 1^{*} 03011$ gene and of Alu29 from the HLA-DRB2 gene are highlighted.

taxonomical groups and have persisted to the present day. Responsible for the phylogenies are sequence motifs shared between exon 2 segments of not only primates, but often also different orders of eutherian mammals (Andersson et al. 1987; Gustafsson and Andersson 1994). However, as discussed elsewhere (Kriener et al. 2000a, b), there is now compelling evidence available in support of the notion that the sharing of motifs is the result of convergent evolution driven by positive selection on exon 2 , which codes for the main functional part of the class II Mhc molecules. Exon 2 sequences are therefore not suitable for phylogenetic analyses of $D R B$ genes. True phylogenies of these genes can be revealed by the intron sequences and corroborated by the distribution and identities of the $A l u$ elements inserted into them.

\section{METHODS}

\section{Source of DNA}

Genomic NWM DNA was isolated from peripheral blood leukocytes of one cotton-top tamarin (Saguinus oedipus, Saoe; Universität Bielefeld, Germany), two common marmosets (Callithrix jacchus, Caja), one common squirrel-monkey (Saimiri sciureus, Sasc; both TNO Institute of Applied Radiobiology and Immunology, Rijswijk, The Netherlands), one black-capped capuchin (Cebus apella, Ceap), and two dusky titis (Callicebus moloch, Camo; both Universität Kassel, Ger- many). [The species abbreviations listed in parentheses are in accordance with the rules for standardized Mhc nomenclature (Klein et al. 1990)]. Prosimian DNA was prepared from one Philippine tarsier (Tarsius syrichta, Tasy), one Horsfield's tarsier (Tarsius bancanus, Taba; both CNRS Paris, France), and one moholi bushbaby (Galago moholi, Gamo; Universität Kassel). The DNA was extracted according to the protocol of Blin and Stafford (1976).

\section{PCR}

Fifty to one hundred nanograms of genomic DNA were amplified with $0.5 \mu \mathrm{M}$ of each of the two primers (Table 1; Fig. 4), $200 \mu \mathrm{M}$ of each of the four deoxyribonucleotide phosphates, and $1.5 \mathrm{mM} \mathrm{MgCl}_{2}$ in the form of Hot Wax $\mathrm{Mg}^{2^{+}}$beads (Invitrogen, Leek, The Netherlands) using the GeneAmp XL PCR Kit (Perkin Elmer Applied Biosystems, Foster City, CA). The amplification was performed in the Gene Amp PCR System 9600 (Perkin Elmer Cetus, Norwalk, CN) and consisted of 12 cycles of denaturation at $94^{\circ} \mathrm{C}$ for $30 \mathrm{sec}$, followed by annealing and extension at $64^{\circ} \mathrm{C}$ for $8 \mathrm{~min}$, then 24 cycles, in which the annealing temperature was raised by $0.15^{\circ} \mathrm{C}$ in every cycle. The reaction was completed by a final primer extension for $10 \mathrm{~min}$ at $72^{\circ} \mathrm{C}$. The amplification products were purified and cloned in the SmaI site of the pGEM-3Zf $(+$ ) (Promega, Madison, WI) or the pUC18 plasmid vector (Amersham Pharmacia Biotech, Freiburg, Germany).

\section{DNA Sequencing}

Double-stranded DNA was prepared with the QIAgen Plasmid Kit (Qiagen, Hilden, Germany) and sequenced by using the AutoRead Sequencing Kit (Amersham Pharmacia Biotech). Five microliters of each sequencing reaction mixture were loaded on a $6.6 \%$ acrylamide gel and run in the Automated Laser Fluorescent DNA sequencer (Amersham Pharmacia Biotech). Cycle sequencing reactions were performed with the 7-deaza-dGTP Kit (Amersham Pharmacia Biotech) and run in the LiCor sequencer (MWG Biotech, Ebersberg, Germany).

\section{Restriction Enzyme Digestion and Southern Blotting}

Clones were digested with the restriction enzyme combinations BamHI/HindIII, HindIII/HincII, and BamHI/EcoRI (NEB, Beverly, MA; Boehringer, Mannheim, Germany) according to the manufacturer's instructions. After $1 \mathrm{hr}$ of incubation, the digestion products were separated on a $1 \%$ agarose gel and transferred to positively charged nylon membranes (Hybond $\mathrm{N}^{+}$, Amersham Pharmacia Biotech or Gene Screen Plus, NEN, Boston, MA) by alkaline vacuum blotting with $0.4 \mathrm{~N} \mathrm{NaOH}$ as a transfer solution.

\section{Hybridization}

A hybridization probe was obtained by PCR amplification of human genomic DNA using primers Alu1 and Alu2. The primers bound to the $5^{\prime}$ and $3^{\prime}$ ends of a dimeric Alu element, respectively, and amplified a 250-bp fragment. The PCR product was labeled with $\alpha\left[{ }^{32} \mathrm{PdCTP}\right]$ by using Ready-To-Go DNA labeling beads (Amersham Pharmacia Biotech). Prehybridization was carried out for 1 or $2 \mathrm{hr}$ at $42^{\circ} \mathrm{C}$ in a solution containing 50\% formamide, 5x SSPE, 5x Denhardt's solution, $0.1 \%$ SDS, and $100 \mu \mathrm{g} / \mathrm{ml}$ sonicated salmon sperm DNA. The hybridization probe was denatured and added to a fresh hybridization solution. Hybridization was carried out overnight at $42^{\circ} \mathrm{C}$. The membranes were washed twice for $15 \mathrm{~min}$ at room temperature in a solution containing $2 \mathrm{x}$ SSPE and $0.2 \%$ SDS, and once for $15 \mathrm{~min}$ at $50^{\circ} \mathrm{C}$ in a solution containing 

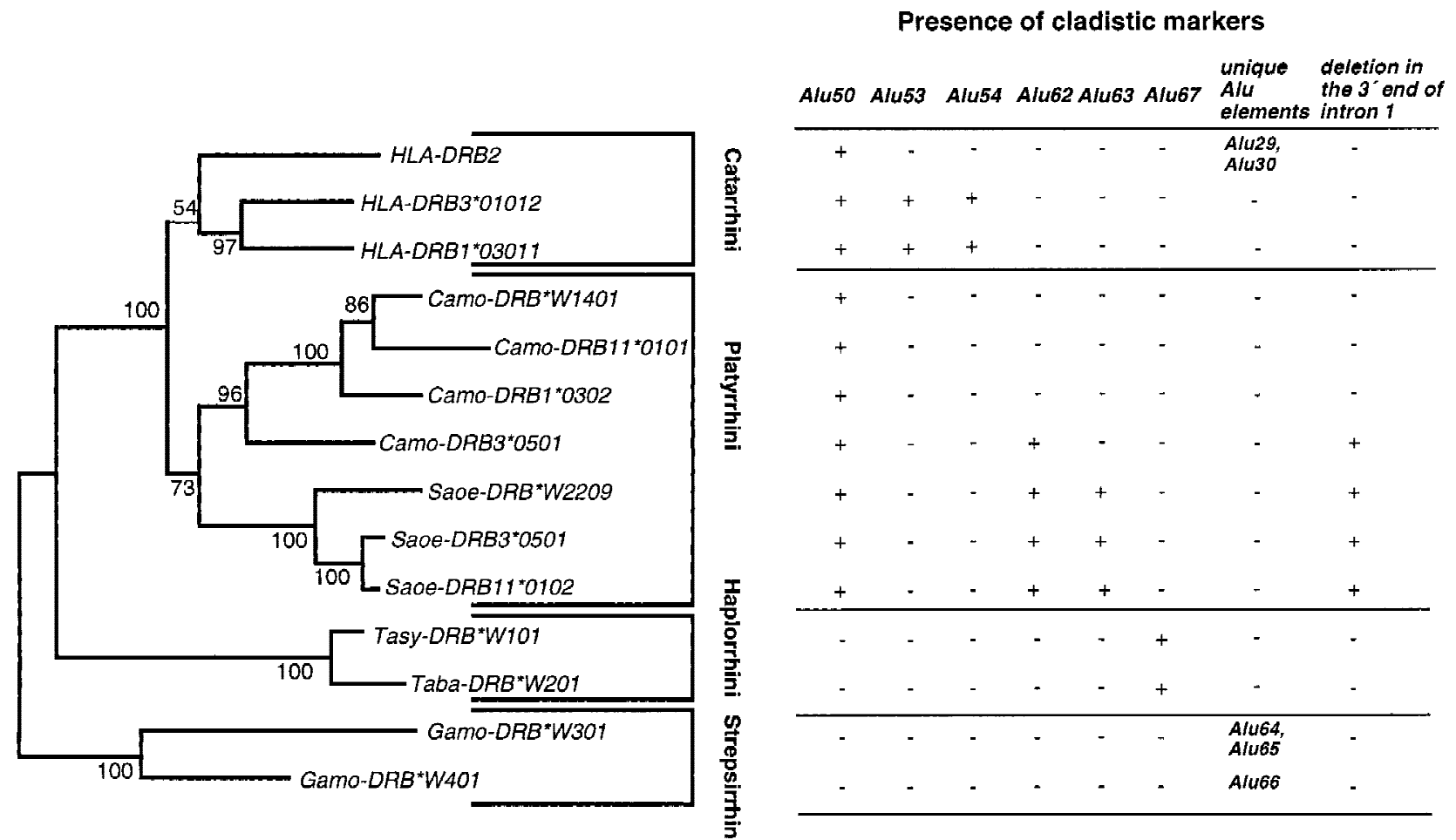

Figure 6 Comparison of a phylogeny obtained by sequence data with the distribution of cladistic markers. The neighbor-joining tree is based on the sequence of the $5^{\prime}$ end of intron 1 in addition to the sequence from the region surrounding the Alu elements. Major primate groupings (Catarrhini, Platyrrhini, Haplorrhini, and Strepsirrhini) correspond to clades indicated on the tree. The numbers at nodes indicate the percentage of recovery of that node in 500 bootstrap replications. The presence and absence of Alu elements and of an $870 \mathrm{bp}$-deletion at the $3^{\prime}$ end of intron 1 are indicated by + and - symbols, respectively. The names of unique Alu elements are given where they occur.

$0.5 \mathrm{x}$ SSPE and $0.2 \%$ SDS. The filters were then used to expose X-ray film (XAR5; Kodak, Stuttgart, Germany). The hybridization-positive restriction fragments thus identified were subcloned and sequenced.

\section{Sequence Analysis and Classification of Alu Elements}

Sequences were scanned by using the program Dotty Plot, version 1.0c (Gilbert 1995a) and aligned with the help of the program SeqPup version 0.4 (Gilbert 1995b). Genetic distances were calculated by the two-parameter method (Kimura 1980). Phylogenetic trees were drawn by the neighbor-joining method (Saitou and Nei 1987) in the version specified by the program MEGA (Kumar et al. 1993) and by the maximum likelihood method using the program PHYLIP (Felsenstein 1993). Alu elements were aligned to the consensus sequence of $A l u$ elements and their flanking direct repeats were identified. They were classified in subfamilies according to Jurka and Milosavljevic (1991).

\section{ACKNOWLEDGMENTS}

We thank Ms. Jane Kraushaar for editorial assistance, Dr. Herbert Tichy, MPI für Biologie, Tübingen for the NWM and prosimian DNA samples, and Dr. Philippe Dijan, CNRS, Paris for providing us with tarsier DNA. The publication costs of this article were defrayed in part by payment of page charges. This article must therefore be hereby marked "advertisement" in accordance with 18 USC section 1734 solely to indicate this fact.

\section{REFERENCES}

Andersson, G., D. Larhammer, E. Widmark, B. Servenius, P.A. Peterson, and L. Rask. 1987. Class II genes of the human major histocompatibility complex. Organization and evolutionary relationships of the DRß genes. J. Biol. Chem. 262: 8748-8758.

Andersson, L., S. Sigurdardóttir, C. Borsch, and K. Gustafsson. 1991 Evolution of MHC polymorphism: Extensive sharing of polymorphic sequence motifs between human and bovine DRB alleles. Immunogenetics 33: 188-193.

Antunes, S.G., N.G. de Groot, H. Brok, G. Doxiadis, A.L. Menezes, N. Otting, and R.E. Bontrop. 1998. The common marmoset: A new world primate species with limited Mhc class II variability. Proc. Natl. Acad. Sci. 95: 11745-11750.

Batzer, M.A., M. Stoneking, M. Alegria-Hartman, H. Bazan, D.H. Kass, T.H. Shaikh, G. E. Novick, P.A. Ioannou, W.D. Scheer, R.J. Herrera, and P.L. Deininger. 1994. African origin of human-specific polymorphic Alu insertions. Proc. Natl. Acad. Sci. 91: 12288-12292.

Batzer, M.A., P.L. Deininger, U. Hellmann-Blumberg, J. Jurka, D. Labuda, C.M. Rubin, C.W. Schmid, E. Zietkiewicz, and E. Zuckerkandl. 1996. Standardized nomenclature for Alu repeats. J. Mol. Evol. 42: 3-6.

Blin, N. and D.W. Stafford. 1976. A general method for isolation of high molecular weight DNA from eukaryotes. Nucleic Acids Res. 3: 2303-2308.

Carson, S. and J. Trowsdale. 1986. Molecular organization of the class II genes of the human and mouse major histocompatibility complexes. In Oxford surveys on eukaryotic genes(ed. N. Maclean), Vol. 3, pp. 63-94. Oxford University Press, Oxford, UK.

Daniels, G.R. and P.L. Deininger. 1985. Repeat sequence families derived from mammalian tRNA genes. Nature 317: 819-822. 
. 1991. Characterization of a third major SINE family of repetitive sequences in the galago genome. Nucleic Acids Res. 19: $1649-1656$

Deininger, P.L. and M.A. Batzer. 1993. Evolution of Retroposons. In Evolutionary biology, (ed. M.K. Hecht), Vol. 27, pp. 157-196. Plenum Press, New York, NY.

Felsenstein, J. 1993. PHYLIP (phylogeny inference package) Version 3.5c. University of Washington, Seattle, WA.

Figueroa, F., C. O'hUigin, H. Tichy, and J. Klein. 1994. The origin of primate $M h c-D R B$ genes and allelic lineages as deduced from the study of prosimians. J. Immunol. 152: 4455-4465.

Gilbert, D.G. 1995a. DottyPlot, version 1.0c, http://iubio.bio.indiana. edu/soft/molbio.

- 1995b. SeqPup version 0.4j: a biosequence editor and analysis application. http://iubio.bio.indiana.edu/soft/molbio

Goodman, M., C.A. Porter, J. Czelusniak, S.L. Page, H. Schneider, J. Shoshani, G. Gunnell, and C.P. Groves. 1998. Toward a phylogenetic classification of primates based on DNA evidence complemented by fossil evidence. Mol. Phylogenet. Evol 9: $585-598$.

Gustafsson, K. and L. Andersson. 1994. Structure and polymorphism of horse MHC class II DRB genes: Convergent evolution in the antigen binding site. Immunogenetics 39: 355-358.

Gyllensten, U.B., T. Bergström, A. Josefsson, M. Sundvall, A. Savage, E.S. Blumer, L. Humberto Giraldo, L.H. Soto, and D.I. Watkins. 1994. The cotton-top tamarin revisited: Mhc class I polymorphism of wild tamarins, and polymorphism and allelic diversity of the class II $D Q A 1, D Q B 1$, and $D R B$ loci. Immunogenetics 40: 167-176.

Hamdi, H., H. Nishio, R. Zielinski, and A. Dugaiczyk. 1999. Origin and phylogenetic distribution of Alu DNA repeats: Irreversible events in the evoltion of primates. J. Mol. Biol. 189: 861-871.

Hughes, A.L. and M. Nei. 1989a. Evolution of the major histocompatibility complex: Independent origin of nonclassical class I genes in different groups of mammals. Mol. Biol. Evol. 6: $559-579$.

- 1989b. Nucleotide substitution at major histocompatibility complex class II loci: Evidence for overdominant selection. Proc. Natl. Acad. Sci. 86: 958-962.

Jurka, J. 1995. Origin and evolution of Alu repetitive elements. In The impact of short interspersed elements (SINEs) on the host genome (ed. R.J. Maraia), pp. 25-41. R.G. Landes Company, Ausin, TX, USA.

Jurka, J. and A. Milosavljevic. 1991. Reconstruction and analysis of human Alu genes. J. Mol. Evol. 32: 105-121.

Kasahara, M., M.F. Flajnik, T. Ishibashi, and T. Natori. 1995. Evolution of the major histocompatibility complex: A current overview. Transpl. Immunol. 3: 1-20.

Kimura, M. 1980. A simple method for estimating evolutionary rates of base substitutions through comparative studies of nucleotide sequences. J. Mol. Evol. 16: 111-120.

Klein, J. 1986. Natural history of the major histocompatibility complex, John Wiley, New York, NY.

Klein, J. and F. Figueroa. 1986. Evolution of the major histocompatibility complex. CRC Crit. Rev. Immunol. 6: 295-386.

Klein, J., R.E. Bontrop, R.L. Dawkins, H.A. Erlich, U.B. Gyllensten, E.R. Heise, P.P. Jones, P. Parham, E.K. Wakeland, and D.I. Watkins. 1990. Nomenclature for the major histocompatibility complexes of different species: a proposal. Immunogenetics 31: $217-219$

Klein, J., C. O'hUigin, M. Kasahara, V. Vincek, D. Klein, and F. Figueroa. 1991. Frozen haplotypes in Mhc evolution. In Molecular evolution of the major histocompatibility complex (ed. J. Klein and D. Klein), pp. 261-286. Springer-Verlag, Heidelberg, Germany.

Klein, J., H. Ono, D. Klein, and C. O'hUigin. 1993. The accordion model of Mhc evolution. In Progress in immunology (ed. J. Gergely and G. Petranyi), pp. 137-143. Springer-Verlag, Heidelberg, Germany.

Knapp, L.A., L.F. Cadavid, M.E. Eberle, S.J. Knechtle, R.E. Bontrop, and D.I. Watkins. 1997. Identification of new Mamu-DRB alleles using DGGE and direct sequencing. Immunogenetics 45: 171-179.
Kriener, K., C. O'hUigin, and J. Klein. 2000a. Conversion or convergence? Introns of primate $D R B$ genes tell the true story. In The major histocompatibility complex: Evolution, structure, and function (ed. M. Kasahara), pp. 354-376. Springer-Verlag, Tokyo, Japan.

Kriener, K., C. O’hUigin, H. Tichy, and J. Klein. 2000b. Convergent evolution of major histocompatibility complex molecules in humans. Immunogenetics 51: 169-178.

Kumar, S., K. Tamura, and M. Nei. 1993. MEGA: Molecular evolutionary genetic analysis, version 1.01, The Pennsylvania State University, University Park, PA.

Kupfermann, H., Y. Satta, N. Takahata, H. Tichy, and J. Klein. 1999. Evolution of $M h c-D R B$ introns: Implications for the origin of primates. J. Mol. Evol. 48: 663-674.

Martin, R.D. 1990. Primate origins and evolution: A phylogenetic reconstruction, Chapman and Hall, London, UK.

Mňuková-Fajdelová, M., Y. Satta, C. O’hUigin, W.E. Mayer, F. Figueroa, and J. Klein. 1994. Alu elements of the primate major histocompatibility complex. Mamm. Genome 5: 405-415.

Nikaido, M., A. Rooney, and N. Okada. 1999. Phylogenetic relationships among cetartiodactyls based on insertions of short and long interspersed elements: Hippopotamuses are the closest extant relatives of whales. Proc. Natl. Acad. Sci. 96: 10261-10266.

O'hUigin, C. 1995. Quantifying the degree of convergence in primate Mhc-DRB genes. Immunol. Rev. 143 123-140.

Parham, P. 1999. Immunological reviews, Vol. 167, Munksgaard International Publishers Ltd., Copenhagen, Denmark.

Quentin, Y. 1992a. Fusion of a free left Alu monomer and a free right Alu monomer at the origin of the Alu family in the primate genomes. Nucleic Acids Res. 20: 487-493.

Quentin, Y. 1992b. Origin of the Alu family: A family of Alu-like monomers gave birth to the left and the right arms of the Alu elements. Nucleic Acids Res. 20: 3397-3401.

Saitou, N. and M. Nei. 1987. The neighbor-joining method: A new method for reconstructing phylogenetic trees. Mol. Biol. Evol. 4: 406-425.

Satta, Y., W.E. Mayer, and J. Klein. 1996a. HLA-DRB intron 1 sequences: Implications for the evolution of HLA-DRB genes and haplotypes. Hum. Immunol. 51: 1-12.

. 1996b. Evolutionary relationships of HLA-DRB genes inferred from intron sequences. J. Mol. Evol.42: 648-657.

Schönbach, C. and J. Klein. 1991. The Alu repeats of the primate DRB genes. In Molecular evolution of the major histocompatibility complex (ed. J. Klein and D. Klein), pp. 243-255. Springer-Verlag, Heidelberg, Germany.

Shimamura, M., H. Yasue, K. Ohshima, H. Abe, H. Kato, T. Kishiro, M. Goto, I. Munechika, and N. Okada. 1997. Molecular evidence from retroposons that whales form a clade within even-toed ungulates. Nature 388: 666-670.

Slierendregt, B.L., J.T. van Noort, R.M. Bakas, N. Otting, M. Jonker, and R.E. Bontrop. 1992. Evolutionary stability of trans-species major histocompatibility complex class II $D R B$ lineages in man and rhesus monkey. Hum. Immunol. 35: 29-39.

Stoneking, M., J.J. Fontius, S.L. Clifford, H. Soodyall, S.S. Arcot, N. Saha, T. Jenkins, M.A. Tahir, P.L. Deininger, and M.A. Batzer. 1997. Alu insertion polymorphisms and human evolution: Evidence for a larger population size in Africa. Genome Res. 7: 1061-1071.

Trtková, K., H. Kupfermann, B. Grahovac, W.E. Mayer, C. O’hUigin, H. Tichy, R.E. Bontrop, and J. Klein. 1993. Mhc-DRB genes of platyrrhine primates. Immunogenetics 38: 210-222.

Trtková, K., Y. Satta, W.E. Mayer, C. O’hUigin, and J. Klein. 1995. Mhc-DRB genes and the origin of New World monkeys. Mol. Phylogenet. Evol. 4: 408-419.

Ullu, E. and C. Tschudi. 1984. Alu sequences are processed 7SL RNA genes. Nature 312: 171-172.

Zietkiewicz, E., C. Richer, and D. Labuda. 1999. Phylogenetic affinities of tarsier in the context of primate Alu repeats. Mol. Phylogenet. Evol. 11: 77-83.

Received October 4, 1999; accepted in revised form January 18, 2000. 


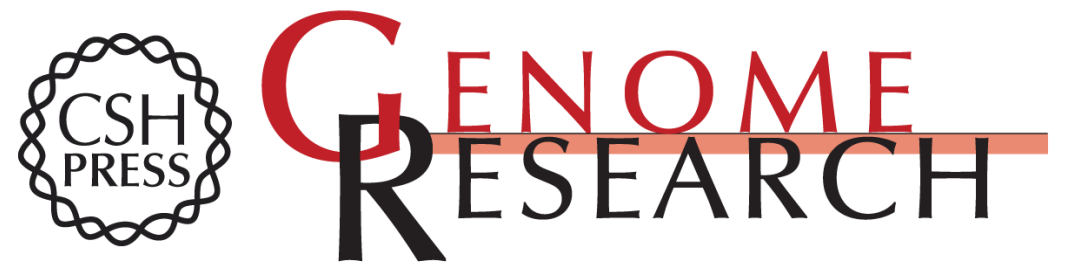

\section{Alu Elements Support Independent Origin of Prosimian, Platyrrhine, and Catarrhine Mhc-DRB Genes}

Karin Kriener, Colm O'hUigin and Jan Klein

Genome Res. 2000 10: 634-643

Access the most recent version at doi:10.1101/gr.10.5.634

References This article cites 37 articles, 7 of which can be accessed free at: http://genome.cshlp.org/content/10/5/634.full.html\#ref-list-1

\section{License}

Email Alerting Receive free email alerts when new articles cite this article - sign up in the box at the Service top right corner of the article or click here.

\section{Affordable, Accurate Sequencing.}

